\title{
Explosive-driven shock wave and vortex ring interaction with a propane flame
}

\author{
P. M. Giannuzzi ${ }^{1}$ - M. J. Hargather ${ }^{2}$ - G. C. Doig ${ }^{3,4}$
}

\begin{abstract}
Experiments were performed to analyze the interaction of an explosively driven shock wave and a propane flame. A $30 \mathrm{~g}$ explosive charge was detonated at one end of a 3-m-long, 0.6-m-diameter shock tube to produce a shock wave which propagated into the atmosphere. A propane flame source was positioned at various locations outside of the shock tube to investigate the effect of different strength shock waves. High-speed retroreflective shadowgraph imaging visualized the shock wave motion and flame response, while a synchronized color camera imaged the flame directly. The explosively driven shock tube was shown to produce a repeatable shock wave and vortex ring. Digital streak images show the shock wave and vortex ring propagation and expansion. The shadowgrams show that the shock wave extinguishes the propane flame by pushing it off of the fuel
\end{abstract}

Communicated by A. Higgins.



M. J. Hargather

mjh@nmt.edu

P. M. Giannuzzi

pmgiannuzzi@gmail.com

G. C. Doig

gcdoig@ calpoly.edu

1 Energetic Materials Research and Testing Center (EMRTC), New Mexico Tech, 801 Leroy Place, Socorro, New Mexico 87801, USA

2 Mechanical Engineering Department and EMRTC, New Mexico Tech, 801 Leroy Place, Socorro, New Mexico 87801, USA

3 Aerospace Engineering Department, California Polytechnic State University, 1 Grand Ave, San Luis Obispo, California 93407, USA

4 School of Mechanical and Manufacturing Engineering, University of New South Wales, Sydney, NSW 2052, Australia source. Even a weak shock wave was found to be capable of extinguishing the flame.

Keywords Shadowgraph · Vortex ring · Flame extinguishment $\cdot$ Explosive shock wave $\cdot$ Flow visualization

\section{Introduction}

Little is known about the interaction of shock waves and high-speed vortex rings with turbulent flames in an open atmosphere, despite the use of high explosives to extinguish wild oil and gas well fires [1,2]. Wild oil well fires, characterized by an enormous flow rate of fuel, make extinguishment difficult using conventional methods. Explosives-and the flow features they generate-were efficient at extinguishing fires, thus allowing safe human access to stop the flow of fuel. Experiments have documented the ability to extinguish largescale oil well [3-5] and forest [6] fires with explosives, and analysis has indicated that the techniques could be broadly successful. However, there has been a lack of satisfactory evidence of the time-resolved mechanisms of extinguishment or differentiation between possible extinguishment scenarios have not been presented. The exact mechanisms of extinguishment have thus remained poorly characterized until recently $[7,8]$.

Much work has been performed to understand the nature of shock/fuel/flame interactions for propulsion and flames in channels, including deflagration to detonation transition. These studies, however, tend to be of small scale and almost entirely physically constrained within pipes and combustion chambers $[9,10]$. A shock generated explosively and allowed to exhaust to the atmosphere from a closed (shock) tube, however, creates external, three-dimensionally propagating flow features with decaying intensity. The formation of vor- 
tex rings at the exhaust is a signature process and evolves differently in the compressible and incompressible regimes $[11,12]$. Objects downstream of the shock tube will experience a nominally planar shock front, then a high-speed, high-impulse flow following it ("blast wind"), and finally a vortex ring with induced and entrained rotating flows, often characterized further by an embedded shock and additional vortices $[13,14]$.

Doig et al. $[7,8]$ investigated shock tube-generated scenarios and found multiple means of flame extinguishment in small-scale experiments. The shock tube used was compressed air driven with a 0.044 by $0.047 \mathrm{~m}$ rectangular cross section. Shock Mach numbers between 1.1 and 1.5 were studied for their interactions with laminar Bunsen flames at various on- and off-axis locations, using high-speed schlieren and limited high-frequency pressure sensing. The schlieren imaging revealed that the passage of the shock itself through the flame did not have any immediate appreciable effect on the flame structure other than a slight compression of the flame (with presumably an increased rate of combustion as a result). The vortex ring and expanding gas jet following the shock were determined to be responsible for all observed extinguishments.

Direct vortex interaction with the flame was observed to rotate and disintegrate the flame structure into turbulent incoherence, followed by extinguishment even if the heat remained over the continuing fuel supply. The flame was extinguished even when significantly (18 burner diameters) off-axis from the vortex path, due to entrainment of fluid by the vortex ring reaching a critical level of instantaneous angular velocity [15]. The embedded shock and secondary and tertiary vortices accompanying the main ring may have had an effect on the rate of cessation of combustion in the instances where the vortex-induced response was found to be the pri- mary mechanism of flame extinguishment. It was unclear as to whether the observed phenomena would scale up.

In the present work, visualization and characterization of supersonic flow created by an explosively driven shock tube (Friedlander blast profile) interacting with a propane flame approximately an order of magnitude greater in size than the previous laboratory studies [16] is presented. The vortex ring produced in these studies was found to be of little influence in extinguishing the flames in all scenarios tested, and unlike the compressed air tests there was not a strong, sustained supersonic central jet. Therefore, the focus here is on the shock wave and the following subsonic "blast wind" as being the fundamental influences on the flame and its extinguishment.

\section{Experimental methods}

Experiments were performed at the Energetic Materials Research and Testing Center (EMRTC) at New Mexico Tech in Socorro, New Mexico, USA. All tests were performed at an outdoor test site, shown schematically in Fig. 1.

\subsection{Explosive-driven shock tube}

A 0.61 -m-diameter, 3.05-m-long shock tube was used to direct an explosively driven shock wave toward the propane flame source. The shock tube was made of $9.5 \mathrm{~mm}$ steel and was elevated so that the axis of the tube was $1.22 \mathrm{~m}$ above the ground to reduce the influence of shock wave ground reflections. The end of the tube facing the flame source was open and the other end was blocked with a 36-kg inertial wall which helped to direct more of the explosion energy forward toward the flame source.

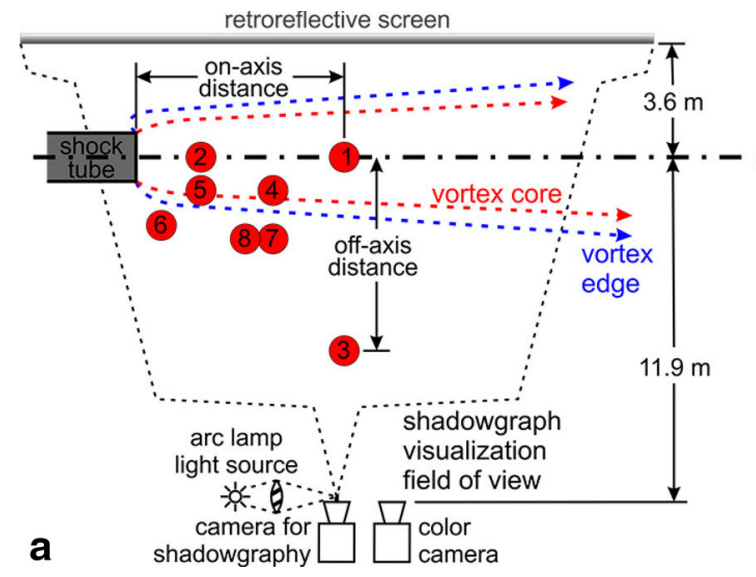

Fig. 1 a Schematic of the test setup and $\mathbf{b}$ image of the shock tube, propane burner and flame, and retroreflective screen. The schematic shows each of the burner locations (numbered circles) to scale and the overall shadowgraph system which has been vertically compressed. The

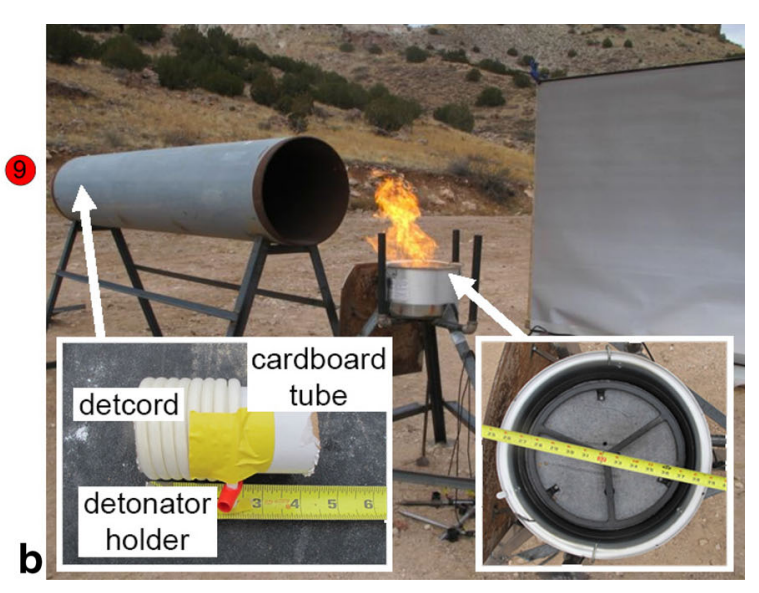

measured paths of the vortex core and edge are illustrated by dashed lines. The insets on $\mathbf{b}$ show the (left) explosive charge and (right) propane burner top view 
The explosive charge was a 1.42 m length of 100 grain detcord initiated with an RP-80 detonator, providing $30 \mathrm{~g}$ of PETN explosive. The detcord was tightly wrapped around a 0.05-m-diameter cardboard tube, as shown in the left inset of Fig. 1b. The charge was centered along the axis of the shock tube, a distance of $0.20 \mathrm{~m}$ from the closed shock tube end. When positioned further down the shock tube, multiple shock waves were observed exiting, and if placed closer to the closed end, significant damage occurred to the end wall. Initial experiments showed that the compact detcord wrapping, position of the explosive charge, and the length of the shock tube were sufficient to result in a single, nearly planar shock wave exiting the shock tube.

Three $345 \mathrm{kPa}$ PCB model 137B23 blast pressure pencil gages were used to record free-field static pressures at $500 \mathrm{kHz}$ during the tests. These gages were mounted on the burner stand, above the flame base, with a clear line of sight to the shock tube exit. Separate tests were performed with pressure gages and no flame $(\mathrm{P})$ and flame tests with no pressure gages $(\mathrm{F})$. The gages recorded the shock wave pressures, which demonstrated the repeatability of the shock wave peak pressure and exponential decay to within the gage uncertainty of $\pm 3 \mathrm{kPa}$.

\subsection{Propane flame source}

A commercial propane ring burner, shown in Fig. 1b right inset, was used as the flame source in these tests. The burner had a 0.38 -m outer diameter. 1.2-mm-diameter propane ejection holes were distributed across the 0.30-m-diameter inner ring ( 24 holes) and three support arms in a "Y" pattern (40 holes) across the middle of the burner. The burner was mounted such that the top surface of the burner was at the same height as the bottom of the shock tube. Commercial propane was fed from a regulator set at $69 \mathrm{kPa}$ (gage).

\subsection{Retroreflective shadowgraph imaging}

A retroreflective shadowgraph system [17] was used to image the shock wave and flame interactions. Shadowgraphy visualizes shock waves and turbulent eddies clearly, but is incapable of revealing the expansion behind the shock wave or any quantitative density measurements [18]. The 4.88-m-long by 2.44-m-high retroreflective screen was positioned so that the shock tube axis was centered on the vertical height of the screen and the open end of the shock tube was at the edge of the field of view. A Newport-Oriel $1000 \mathrm{~W}$ arc lamp source was focused onto a $45^{\circ}$ rod mirror mounted in front of the camera lens to provide illumination [17]. A Photron SA-X2 high-speed digital camera recorded images at 20,000 frames per second, 1024 by 672 pixel resolution, and $1 \mu$ s exposure for all tests. The camera and light source were elevated on a table to be at the same height as the shock tube centerline.

A Phantom v611 recorded simultaneous color high-speed images of the tests at 20,000 frames per second, 768 by 384 pixel resolution, and $49 \mu$ s exposure. This camera was used to correlate the time of flame extinguishment with the shock motion from the shadowgraph images.

\section{Experimental results}

Table 1 summarizes the tests performed here. The test locations were chosen to include locations: on the axis of the shock tube, along the expected path of the vortex ring, near the vortex ring outer edge (near expected entrainment locations), and far from the vortex ring path. The shadowgraph imaging showed that the shock propagation was the same for all tests up until the interaction with the flame source. Tests validated that the shock propagation and pressure field were highly repeatable. Outdoor test conditions varied slightly in atmospheric temperature (274-285 K), pressure
Table 1 Summary of tests performed

\begin{tabular}{llllll}
\hline Test & Position & Off-axis distance $(\mathrm{m})$ & On-axis distance $(\mathrm{m})$ & Radial distance $(\mathrm{m})$ & Test type \\
\hline 1,2 & 1 & 0 & 2.63 & 2.63 & $\mathrm{P}, \mathrm{P}$ \\
3,4 & 1 & 0 & 2.63 & 2.63 & $\mathrm{~F}, \mathrm{~F}$ \\
5,6 & 2 & 0 & 0.82 & 0.82 & $\mathrm{P}, \mathrm{F}$ \\
7,8 & 3 & 2.44 & 2.63 & 3.59 & $\mathrm{P}, \mathrm{F}$ \\
9,10 & 4 & 0.42 & 1.73 & 1.78 & $\mathrm{P}, \mathrm{F}$ \\
11,12 & 5 & 0.42 & 0.82 & 0.92 & $\mathrm{P}, \mathrm{F}$ \\
13,14 & 6 & 0.86 & 0.32 & 0.92 & $\mathrm{P}, \mathrm{F}$ \\
15,16 & 7 & 1.03 & 1.73 & 2.01 & $\mathrm{P}, \mathrm{F}$ \\
17,18 & 8 & 1.03 & 1.38 & 1.72 & $\mathrm{P}, \mathrm{P}$ \\
19,20 & 8 & 1.03 & 1.38 & 1.72 & $\mathrm{~F}, \mathrm{~F}$ \\
21 & 9 & 0.76 & 7.81 & 7.85 & $\mathrm{~F}$ \\
\hline
\end{tabular}


$(102 \pm 5 \mathrm{kPa}$ ), and wind (which was less than $5 \mathrm{~m} / \mathrm{s}$ ), but the flame attachment and response were not found to be affected. All calculations of Mach number were made using the temperature at the individual test time.

\subsection{Shock wave propagation}

A sequence of images from test 10 is shown in Fig. 2. The images show the shock wave emerging from the shock tube and propagating spherically downstream. The air within the shock tube, which has been accelerated by the shock wave, exits and forms a large vortex ring which grows as it propagates downstream. The shock wave impinges on the flame source and pushes the flame downstream and eventually off the burner. When the flame moves off the burner, it extinguishes. The flame is extinguished as the vortex ring arrives at the burner location, but the vortex has not directly interacted with the flame. This can be observed in the final image of Fig. 2 where the thermal plume from the now-extinguished flame is still to the right of the leading edge of the vortex ring, with no apparent mixing at this point. This extinguishment method was observed in all of the tests reported, other than test 21 (position 9) in which the flame was not extinguished.

The shock wave ground reflection is clearly observed in Fig. 2 at $t^{*}=2.9$ and $t^{*}=4.4$. In the analysis of the highspeed images, the reflected shock wave is extremely weak and does not appear to affect the flame in any noticeable way (no motion of the flame or lift-off).

The shock wave position versus time was measured from the shadowgraph images $[17,19]$. The shock wave velocity and Mach number were calculated using a centered finite difference. The shock wave Mach number versus distance from the shock tube exit is shown in Fig. 3 for five representative tests. All other test data not shown lie within the shown variability. The spread in the data represents the discretization due to the finite difference calculation and the image pixel resolution of approximately $3.0 \mathrm{~mm} /$ pixel, which yields a Mach number discretization of 0.087 . The data show that the shock wave propagation between tests is highly repeatable, with variation in the measured shock location of less than $\pm 5 \mathrm{~mm}$.

The shock wave exits the tube at a nearly constant Mach number of about 1.9, then decays toward Mach 1 . The initially constant shock velocity is attributed to the shock tube producing a planar shock wave which exits the tube as a one-dimensional shock wave, then becomes spherical as it propagates into the free field. The shock wave velocity begins to decrease at approximately $0.3 \mathrm{~m}$ from the shock tube exit, which is approximately equal to the radius of the shock tube. After this point, the shock wave velocity decays similar to a free-field explosion.
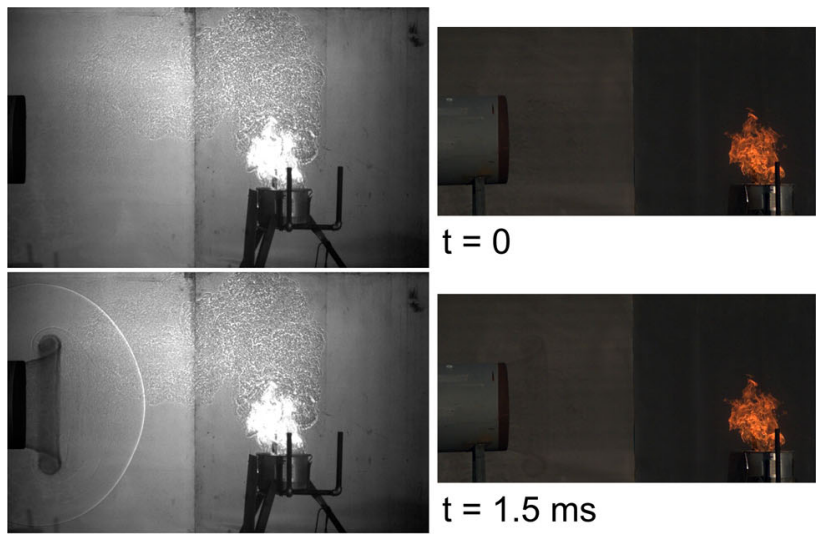

$\mathrm{t}=0$
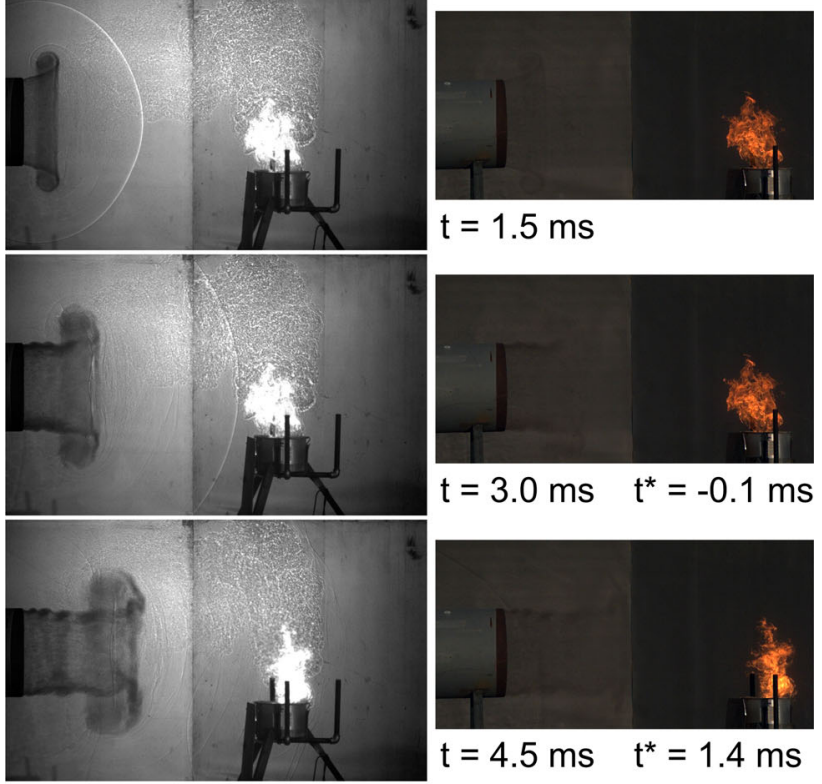

$\mathrm{t}=1.5 \mathrm{~ms}$
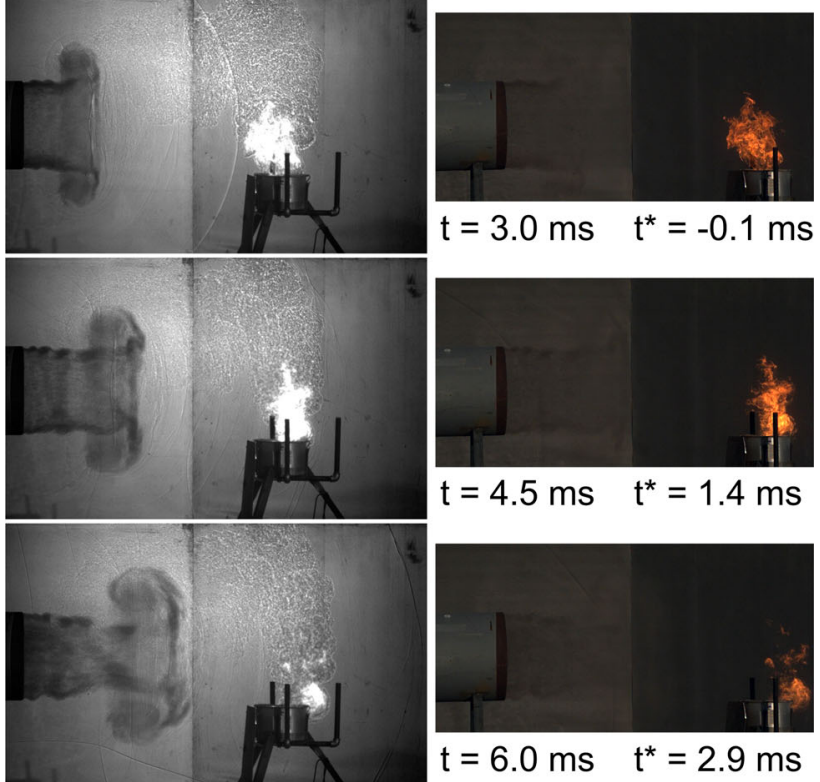

$\mathrm{t}=3.0 \mathrm{~ms} \quad \mathrm{t}^{*}=-0.1 \mathrm{~ms}$
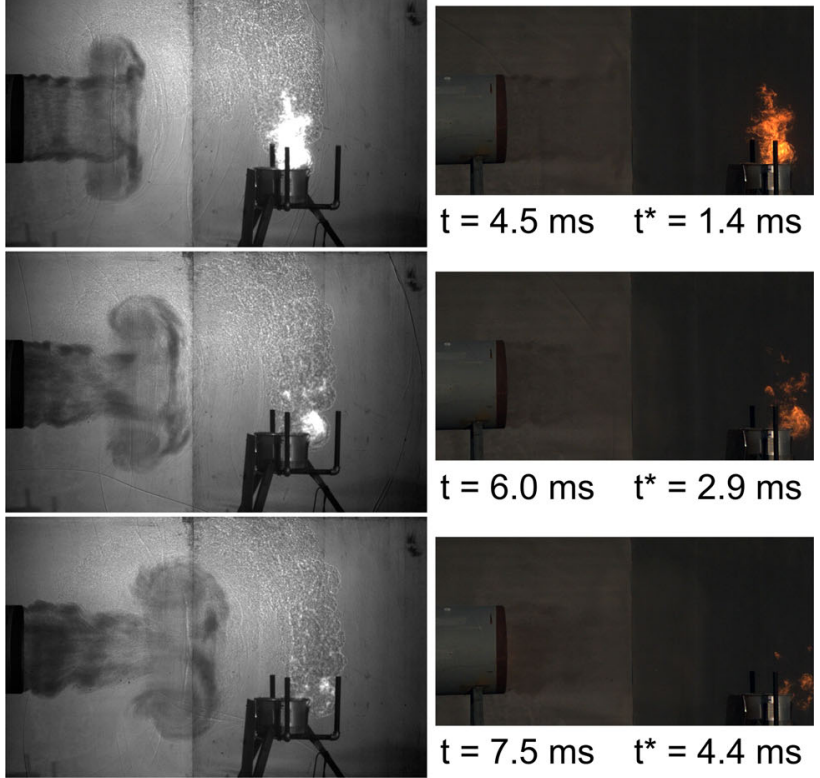

$\mathrm{t}=4.5 \mathrm{~ms} \quad \mathrm{t}^{*}=1.4 \mathrm{~ms}$
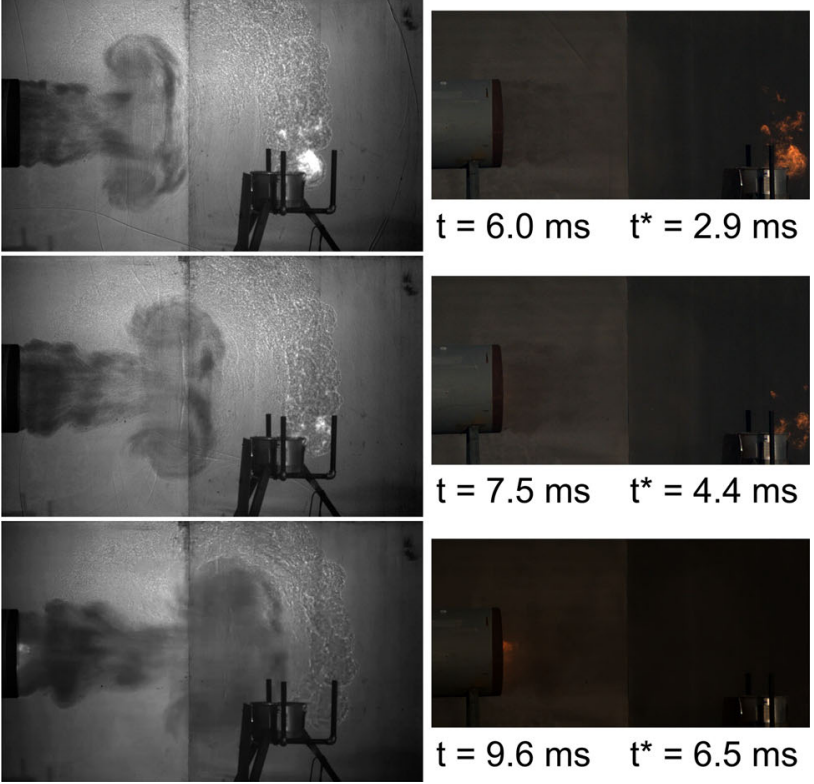

$\mathrm{t}=7.5 \mathrm{~ms} \quad \mathrm{t}^{\star}=4.4 \mathrm{~ms}$

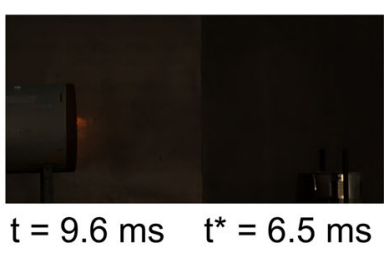

Fig. 2 Image sequence for Test 10 showing the simultaneous (left) shadowgraph and (right) color high-speed images. The images are $1.5 \mathrm{~ms}$ apart, with the first frame representing $t=0$ which is the frame before the shock wave emerges from the shock tube. The shock first interacts with the flame at $t^{*}=0 \mathrm{~ms}$, which is shortly after the third image. The shock has just exited the flame at $t=4.5 \mathrm{~ms}$ and is at the left edge of the field of view at $t=6.0 \mathrm{~ms}$. The flame is almost fully extinguished in the second-to-last frame here and is fully extinguished at $t^{*}=6.5 \mathrm{~ms}$, which is the final image 


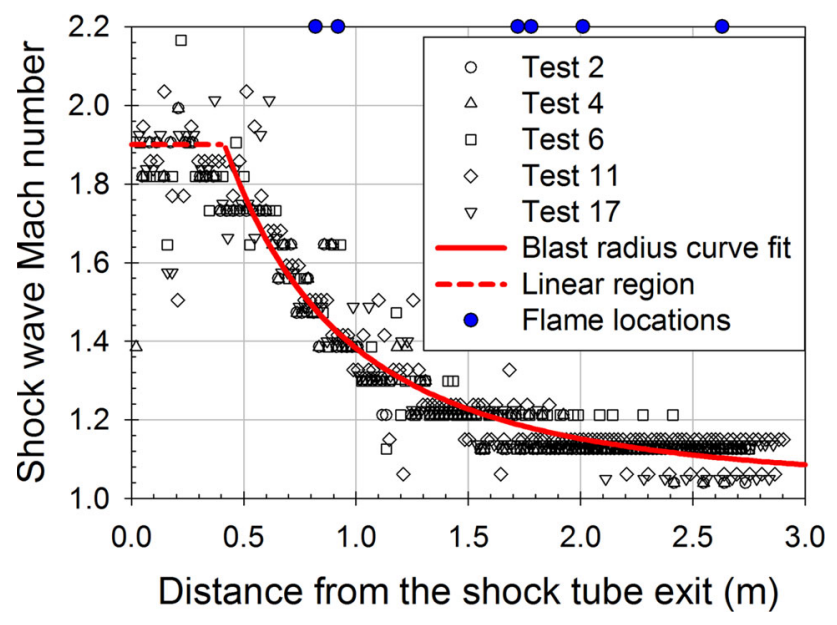

Fig. 3 Graph of shock wave Mach number versus distance from the shock tube exit. The symbols along the top of the graph show the burner locations tested

The experimental data for the shock position, after a distance of $0.3 \mathrm{~m}$ from the shock tube exit, were fit using a least-squares regression to the equation proposed by Dewey for the shock wave radius $(R)$ versus time $(t)$ for a free air blast [20]:

$$
R=A+B a_{0} t+C \ln \left(1+a_{0} t\right)+D \sqrt{\ln \left(1+a_{0} t\right)} .
$$

The resulting coefficients were: $A=-0.354, B=1$, $C=-0.399, D=1.343$, and the parameter $a_{0}=340 \mathrm{~m} / \mathrm{s}$. The curve, plotted in Fig. 3, approximates the shock wave velocity decay well, which is expected once the shock wave becomes spherical. The curve fit is used to calculate the shock wave Mach number at each burner location in Table 2. The radial distance in Tables 1 and 2 represents the straight line distance from the center of the shock tube exit plane to the burner.

The color high-speed videos were analyzed to estimate the amount of time from when the shock wave initially contacts the flame to when the flame is completely extinguished. The results in Table 2 show that the flame is generally extinguished faster when the Mach number of the shock wave is higher. The flame is also extinguished faster if it is on axis with the shock tube. The uncertainty in the flame extinguishment measurements is estimated to be \pm 0.25 ( 5 frames) from the manual inspection of images.

The gas velocity behind the shock wave, $v_{\mathrm{g}}$ in Table 2, is calculated at each burner location using the Mach number and simple gas dynamic relationships. For all tests, except test 21 , the calculated gas velocity is in excess of $50 \mathrm{~m} / \mathrm{s}$, which explains why the flame is observed to be blown sideways off of the burner and thus extinguished. The error in the air velocity calculation scales with the square of Mach number and is approximately $\pm 25 \mathrm{~m} / \mathrm{s}$ for the values given in Table 2, based on the uncertainty in the Mach number at each location. This error is relatively large due to the pixel resolution and resulting error in calculating shock wave velocities using the finite difference method. This calculated velocity is the instantaneous velocity behind the shock wave. The average velocity that the flame experiences will be lower because the pressure behind the shock wave decays exponentially and the shock wave itself is decelerating.

For test 21, in which the flame was not extinguished, the flame source was almost $8 \mathrm{~m}$ from the shock tube exit and the shock wave Mach number was nearly sonic; therefore, the following air had almost no momentum and did not push the flame off the burner. The upper portion of the flame was extinguished, but the lower portion remained attached to the burner and eventually re-established the full flame. The flame may have remained attached at the base because it was slightly protected by the burner lip.

\subsection{Vortex ring propagation}

The high-speed images of the vortex ring showed that it was a compressible vortex ring, as evidenced by the embedded shock wave and inward bow shock [14]. While there is significant shear layer instability, there does not appear to be any clear emergent counter-rotating vortex or vortices ahead of the main vortex ring. These were observed in the smallscale tests of Doig et al. [8] and could be expected at Mach $>1.6$ exit velocity with a compressed air driver [14], but

Table 2 Time from initial shock interaction with flame and extinguishment

\begin{tabular}{lllllll}
\hline Test & Position & Radial distance $(\mathrm{m})$ & Off-axis distance $(\mathrm{m})$ & Mach \# & Extinguish time, $t^{*}(\mathrm{~ms})$ & velocity gas, $v_{\mathrm{g}}(\mathrm{m} / \mathrm{s})$ \\
\hline 6 & 2 & 0.82 & 0 & 1.48 & 3.6 & 224 \\
12 & 5 & 0.92 & 0.42 & 1.42 & 3.8 & 199 \\
14 & 6 & 0.92 & 0.86 & 1.42 & 5.0 & 199 \\
19 & 8 & 1.72 & 1.03 & 1.19 & 6.5 & 97 \\
10 & 4 & 1.78 & 0.42 & 1.18 & 6.5 & 93 \\
16 & 7 & 2.01 & 1.03 & 1.15 & 10.0 & 78 \\
3 & 1 & 2.63 & 0 & 1.10 & 8.0 & 53 \\
\hline
\end{tabular}


Fig. 4 a Streak image created from Test 11 images showing the shock wave and vortex ring propagation. b Moving streak image, created from pixel columns along the centerline of the vortex ring, showing the vertical spreading of the vortex ring with time

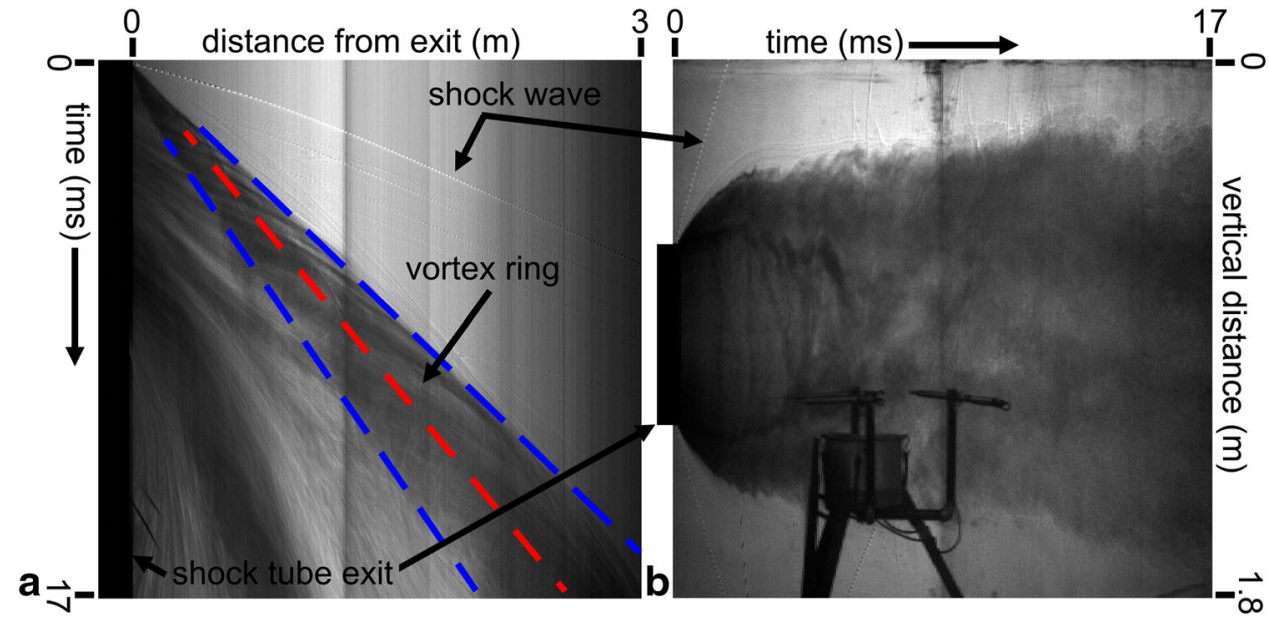

are not present here with the explosive driver. Overall, the vortex ring formation and initial propagation are similar to that described and sketched by Baird [21], but the far-field propagation is expected to be different with the explosive driver.

The vortex ring motion was investigated by creating a digital streak image (Fig. 4a) from the Test 11 image series. The streak image was created by extracting the row of pixels through the center of the shock tube from each high-speed video frame and sequentially vertically stacking them [22]. The streak image shows the shock wave propagation and the vortex ring emerging from the shock tube then propagating downstream at a nearly constant velocity.

The radial spreading of the vortex ring was measured by creating a "moving streak image" (Fig. 4b). This vertical streak image is considered to be "moving" because the column of pixels that is extracted changes with each frame, and in this case is "moving" with the center of the vortex ring. The centerline of the vortex ring was found using Fig. 4a by identifying the leading and trailing edges of the vortex ring on the streak image (blue dashed lines) and using their average as the vortex ring centerline (red dashed line).

Figure $4 \mathrm{~b}$ shows that the vortex ring expands quickly, but then reaches a nearly constant diameter where the core of the vortex ring is approximately $0.7 \mathrm{~m}$ from the shock tube centerline. The measured vortex ring propagation is overlaid on Fig. 1a. Several of the test locations were chosen to have the vortex ring directly interact with the flame source, but results showed that the flame was extinguished before the vortex ring arrived, contrary to previous laboratory results [8].

\section{Conclusions}

Explosively driven shock waves were observed to extinguish flames by blowing the flames off of the fuel source with the velocity that the shock wave imparted to the ambient air. Experiments were performed with varied positions of the flame source relative to the explosively driven shock tube, and in all cases the flame was extinguished by the shock wave and the trailing vortex ring played no role. One test showed no flame extinguishment, with the flame source located almost $8 \mathrm{~m}$ from the shock tube exit. If the imparted air velocity is the only extinguishment mode for all of the scenarios tested, then the minimum air velocity needed to extinguish the flame is between 10 and $40 \mathrm{~m} / \mathrm{s}$.

A method for creating "moving streak images" was presented. This technique was useful for observing the spatiotemporal evolution of the vortex ring. The "moving streak image" is different from a traditional streak image in that the location at which the image is recorded translates during the test.

Acknowledgments Funding was provided by the American Australian Association through a fellowship awarded to G.C. Doig, and UNSW Australia's School of Mechanical and Manufacturing Engineering. We specially thank everyone at EMRTC who assisted with the testing, including N. Canafax, J. Peralta, and R. Weaver.

\section{References}

1. Lesh, F.: Means and method for extinguishing oil well fires. US Patent US2096970 A (1937)

2. Husain, T.: Extinguishing of Kuwait oil fires — challenges, technology, and success. Atmos. Environ. 28(13), 2139-2147 (1994)

3. Akhmetov, D.G., Lugovtsov, B.A., Tarasov, V.F.: Extinguishing gas and oil well fires by means of vortex rings. Combust. Explos. Shock Waves 16(5), 490-494 (1980)

4. Akhmetov, D.G., Lugovtsov, B.A., Maletin, V.A.: Vortex powder method for extinguishing a fire on sprouting gas-oil wells. In: Zarko, V.E., Weiser, V., Eisenreich, N., Vasil'ev, A.A. (eds.) Prevention of Hazardous Fires and Explosions, pp. 319-328. Springer, New York (1999)

5. Xue, Y., Quio, X.H., Jin, G.J.: Research on ignition and extinguishing by explosion of high explosive. Blasting 2, 26-30 (2009)

6. Grishin, A.: Interaction of shockwaves with tree crowns and the front of crown forest fires. In: Brun, R., Dumitrescu, L.Z. (eds.) Shockwaves at Marseille III, pp. 411-416. Springer, New York (1995). doi:10.1007/978-3-642-78835-2_70 
7. Doig, G.C., Johnson, Z., Mann, R.: Shock wave interaction with a flame. In: 18th Australasian Fluid Mechanics Conference (2012)

8. Doig, G.C., Johnson, Z., Mann, R.: Interaction of a shock tube exhaust flow with a non-premixed flame. J. Vis. 16, 173-176 (2013)

9. Kilchyk, V., Nalim, R., Merkle, C.: Laminar premixed flame fuel consumption rate modulation by shocks and expansion waves. Combust. Flame 158(6), 1140-1148 (2011)

10. Kilchyk, V., Nalim, R., Merkle, C.: Scaling interface length increase rates in Richtmyer-Meshkov instabilities. J. Fluids Eng. 135(3), 031,203 (2013)

11. Akhmetov, D.G.: Formation and basic parameters of vortex rings. J. Appl. Mech. Techn. Phys. 42(5), 794-805 (2001)

12. Kashimura, H., Yasunobu, T., Nakayama, H., Setoguchi, T., Matsuo, K.: Discharge of a shock wave from an open end of a tube. J. Therm. Sci. 9(1), 30-36 (2000)

13. Murugan, T., Sudipta, S., Laxmana, D., Das, D.: Numerical simulation and PIV study of formation and evolution of compressible vortex ring. Shock Waves 22(1), 69-83 (2012)

14. Murugan, T., Das, D.: Characteristics of counter-rotating vortex rings formed ahead of a compressible vortex ring. Exp. Fluids 49, 1247-1261 (2010)

15. Dabiri, J.O., Gharib, M.: Fluid entrainment by isolated vortex rings. J. Fluid Mech. 511, 311-331 (2004)
16. Chan, J.E., Giannuzzi, P., Kabir, K.R., Hargather, M.J., Doig, G.: Interactions of shock tube exhaust flows with laminar and turbulent flames In: AIAA SciTech. San Diego, CA, Paper AIAA-2016-1588 (2016)

17. Hargather, M.J., Settles, G.S.: Retroreflective shadowgraph technique for large-scale visualization. Appl. Optics 48, 4449-4457 (2009)

18. Settles, G.S.: Schlieren and shadowgraph techniques: Visualizing phenomena in transparent media. Springer-Verlag, Heidelberg (2001)

19. Hargather, M.J., Settles, G.S.: Optical measurement and scaling of blasts from gram-range explosive charges. Shock Waves 17, 215223 (2007)

20. Dewey, J.M.: Explosive flows: Shock tubes and blast waves. In: Handbook of Flow Visualization, 1st edn., book chapter 29, pp. 481-497. Hemisphere Publishing Corp. (1989)

21. Baird, J.P.: Supersonic vortex rings. Proceedings of the Royal Society of London. Series A, Mathematical and Physical Sciences 409(1836), 59-65 (1987)

22. Kleine, H.: Time-resolved visualization of transient compressible flows. In: 15th International Symposium on Flow Visualization, Minsk, Belarus, Paper ISFV15-158 (2012) 